\section{TRADUZINDO O AUTISMO}

\section{TRANSLATING AUTISM}

Resenha de: RIOS, Clarice; FEIN, Elizabeth (orgs.). 2019. Autismo em tradução: uma conversa intercultural sobre condiçôes do espectro autista. (Trad. João S. Camara; Maria R. Pereira) Rio de Janeiro: Papéis Selvagens. [2018]

\section{Pedro Peixoto Ferreira (1)}

E-mail: ppf@unicamp.br

(1) Professor do Departamento de Sociologia (DS) e do Programa de Pós-Graduação em Sociologia (PPGS) do Instituto de Filosofia e Ciências Humanas (IFCH) da Universidade Estadual de Campinas (UNICAMP), Campinas - SP, Brasil.

DOI: $10.1590 / 3610615 / 2021$

"Autismo" é uma palavra muito ruim para designar o corpo sem órgãos e tudo aquilo que se passa sobre ele, que nada tem a ver com uma vida interior apartada da realidade. (Deleuze 2016, p. 31)

O livro Autismo em tradução: uma conversa intercultural sobre condiçóes do espectro autista (Rio de Janeiro: Papéis Selvagens) é a tradução brasileira do livro original em inglês, publicado em 2018: Autism in translation: an intercultural conversation on autism spectrum conditions (Fein e Rios, 2018). O original já era, em si mesmo, a "tradução" na forma de livro, do encontro Autism Spectrum Disorders: global, local and personal perspectives, que reuniu pesquisadores e porta-vozes do autismo ${ }^{1}$, brasileiros e estrangeiros (principalmente dos EUA e da Itália), por quatro dias na Universidade do Estado do Rio de Janeiro (UERJ), em setembro de 2015 (Fein e Rios, 2016). E o que revela a Introdução das organizadoras do livro (e do encontro), Clarice Rios e Elizabeth Fein, é que o próprio encontro na UERJ, em 2015, também pode ser visto como a "tradução" do encontro entre as duas pesquisadoras, na conferência de $2013 \mathrm{da}$ Society for Psychological Anthropology, em San Diego (Califórnia, EUA). Tradução sobre tradução, do começo ao fim e além (sendo esta resenha ainda mais uma de muitas que certamente virão), este livro é, como bem o disse Kenneth Camargo Jr. em seu prefácio, "um diálogo que se espraia fractalmente" (p.13).

O livro em si, após dois curtos prefácios de Camargo Jr. e de Peter G. Stromberg, e de uma excelente "Introdução" das organizadoras, dividese em três principais partes: "Parte I - Histórias políticas do autismo"; "Parte II - Voz, narrativa e representação"; e "Parte III - O conceito de autismo". Cada uma dessas partes inclui, além de dois ou três capítulos individuais, um "Comentário" final que retoma e desenvolve alguns pontos e questôes ligados aos capítulos. São comentários em geral mais curtos do que os capítulos, que ajudam significativamente a destacar, correlacionar, e mesmo desdobrar, alguns dos temas abordados na respectiva parte. Segue-se a essas, a "Parte IV - Comentários finais", na qual ainda se apresentam dois capítulos bem distintos, mas excelentes, de Thomas S. Weisner e Dawn Prince-Hughes, sobre alguns dos principais temas abordados no livro. A meu ver, o livro encontrou um equilíbrio raro entre abordagens macrossociais (históricas, institucionais, econômicas) e microssociais (etnográficas, poéticas, interacionais) e, também, entre o discurso acadêmico formal e as múltiplas expressóes autistas e "autivistas". Apesar de a maior parte das referências bibliográficas citadas nos capítulos ser $\mathrm{da}$ área da saúde (especialmente psiquiatria, neurologia e saúde coletiva), nota-se ao longo dos capítulos a presença de um corpus bibliográfico consistente proveniente da filosofia e das ciências sociais - com destaque para autores consolidados como Georges Canguilhem, Jacques Derrida, Michel Foucault e Clifford Geertz, mas incluindo, especialmente, contemporâneos que trabalharam com o tema do autismo, como o sociólogo Gil Eyal, a cientista política Chloe Silverman e a antropóloga Elinor Ochs. Com projeto gráfico e diagramático bem resolvido para uma leitura fluente, o livro oferece até mesmo um índice remissivo, raro em publicaçóes nacionais.

$\mathrm{Na}$ Parte I, apresentam-se os dois principais capítulos historiográficos, e com abordagem macrossocial, do livro: Defesa de direitos e politicas para o autismo no Brasil e nos EUA, de Rossano C. Lima, 
Clara Feldman, Cassandra Evans e Pamela Block; e Reforma psiquiátrica e serviços para o autismo na Itália e no Brasil, de M. Ariel Cascio, Bárbara C. Andrada e Benilton Bezerra Jr. São capítulos fundamentais para o leitor leigo nos debates sobre autismo, pois contextualizam e situam histórica e politicamente, em cada um dos três países abordados, suas principais controvérsias atuais. Tomados em conjunto, os dois capítulos sintetizam acontecimentos importantes ligados ao surgimento, e ao estado atual, das pesquisas e contextos sociais do autismo no Brasil, nos EUA e na Itália, desenvolvendo também correlaçóes entre as três diferentes realidades. Os capítulos apresentam o papel de diversas associaçôes e instituiçôes ao longo da história dos três países - no caso do Brasil, por exemplo: a Associação Pestalozzi, nos anos 1930; a Associação de Pais e Amigos de Pessoas Excepcionais (Apae), nos anos 1950; a Associaçáo de Amigos do Autista (AMA), nos anos 1980; e a Associação Brasileira de Autismo (Abra), fundada em 1988; além dos Centros de Assistência Psicossocial (CAPS e CAPSi). Os capítulos também mostram a relação entre o processo de desinstitucionalização de "doentes mentais" e a "epidemia de autismo" observada em cada um dos três países ao longo da segunda metade do século passado e ligada, no Brasil e na Itália, ao movimento de Reforma Psiquiátrica.

Se o capítulo de Cascio e colaboradores chama a atençáo para os diferentes usos políticos do diagnóstico biomédico de Transtorno do Espectro Autista (TEA) por parte de brasileiros e italianos, o de Lima e colegas deixa clara a ausência de consenso sobre os critérios para diagnóstico e tratamento de TEA no Brasil e nos EUA, sugerindo entáo que, "[n]a ausência de consensos sobre esse ponto ["sobre o que uma pessoa com autismo precisa"], nosso conselho é prestar muita atenção ao que querem as pessoas autistas que vivem em cada país" (p.65). Como bem nota Francisco Ortega em seu "Comentário" para esta primeira parte do livro, "Por que não ambos?" Negociando ideias sobre autismo na Itália, no Brasil e nos EUA, o "principal insight" dos dois capítulos é o delineamento de "uma atitude pragmática com relação a categorias diagnósticas, etiologia, serviços, tratamentos e políticas que são negociados por diferentes atores (tanto médicos quanto não médicos) dentro e fora dos serviços de saúde" (p.124), uma atitude que "oferece o potencial de ir além de dicotomias e polarizaçóes, que podem parecer definitivas quando vistas à distância, mas que não são tấo definitivas assim quando examinadas a partir da vida e prática cotidianas dos indivíduos que são mais imediatamente afetados pelo autismo" (p.134).

Dos três capítulos da Parte II, dois evidenciam esforços (bastante distintos) de aproximação entre os modos de produção de conhecimento acadêmicocientífico sobre o autismo e os discursos e práticas dos próprios indivíduos autistas. São os capítulos Música e autismo, representação e re-apresentação: uma perspectiva etnomusicológica, de Michael B. Bakan; e Autismo e relatos em primeira pessoa: o problema cognitivo, de Jurandir F. Costa e Roy R. Grinker. Um "aspecto estrutural crucial" do capítulo de Bakan é o fato de ter sido construído "em torno" de, e "definido por", um texto de "Gordon Peterson (pseudônimo)", no qual aprendemos, entre outras coisas, que ele gostaria, sim, de ter uma "varinha mágica para fazer o TEA desaparecer" (p.152). Se Bakan se apresenta como um "etnomusicólogo do autismo", Gordon Petersen é apresentado como um "multi-instrumentista e musicólogo norte-americano [...] que tem um diagnóstico de Transtorno do Espectro Autista (TEA), mais especificamente, do transtorno antigamente conhecido como Síndrome de Asperger" (p.143). ${ }^{2}$ Costa e Grinker, por sua vez, reuniram trechos selecionados de oito depoimentos em primeira pessoa de pessoas autistas para evidenciar que, apesar de "atípicos", eles são "compreensíveis", e "não deixam de ser racionalmente/cognitivamente coerentes": "seus processos cognitivos podem ser atípicos, mas não são necessariamente indícios de um déficit na 'coerência central'” (p. 202, 213).

O terceiro capítulo da Parte II é Autismo como um modo de engajamento, no qual Elizabeth Fein mobiliza cinco casos etnográficos ligados a crianças e jovens diagnosticados com Síndrome de Asperger (SA), para desenvolver uma surpreendente concepção do autismo como um "modo de engajamento com as coisas do mundo - um modo de estar com aquilo que lhe cerca", "uma forma de permeabilidade, de profunda vulnerabilidade existencial, à ordem das coisas à nossa volta” (p.168). Esse modo de engajamento autista 
envolve, segundo Fein, a mobilização estratégica, para fins expressivos, comunicativos e relacionais, de máquinas e produtos da indústria humana. Por meio de casos etnográficos, Fein mostra como crianças e jovens autistas encontram, na reprodutibilidade técnica, ao mesmo tempo: uma maneira de assimilar, pela repetição, e de reproduzir em ocasiōes específicas, formas cognitivas e expressivas que, de outra forma, talvez não lhe fossem acessíveis; e uma maneira particularmente contemporânea e situada de ser autista, na qual a "repetitividade" e a "rigidez de sua rotinização" podem ser vistas como "o resultado da disponibilidade desses tipos de materiais culturais" e da "capacidade tecnológica sem precedentes de fazer com que as coisas ocorram do mesmo modo todas as vezes" (p.180). Fein mostra uma maneira particular de compreender os descompassos entre os comportamentos autistas e as expectativas sociais mais amplas de flexibilidade e espontaneidade, quando constata que "os produtos culturais que estruturam [esse] comportamento permanecem obstinadamente visíveis como tais, fazendo, portanto, com que confrontemos as formas rígidas, repetitivas e rotinizadas que habitam e ordenam as nossas vidas sociais" (p.187). "Ao patologizar o modo autista" de engajamento com "arranjos específicos de elementos - palavras, conceitos, moléculas, materiais - que são construídos por meio da ação humana", mas que são "descartados e ocluídos", Fein afirma, "perpetuamos nossa habilidade de descartar: manter os subprodutos indesejados da produção humana bem longe de nossas vistas" (p.191). O capítulo de Fein oferece uma potente alternativa às limitaçóes de narrativas neuro-biocêntricas do autismo sobre aquilo que poderíamos chamar de "mente técnica" de pessoas diagnosticadas com SA (e.g.: Baron-Cohen, 2012). A Parte II se fecha com o iluminador Comentário: palavras, voz, silêncio, de Laura Sterponi, no qual aspectos linguísticos e expressivos levantados pelos capítulos são desdobrados, incluindo uma página em branco de "silêncio" (p. 227).

$\mathrm{Na}$ Parte III, encontram-se três abordagens distintas. Em "Expert em seu próprio filho, expert em seu próprio mundo: reinventando a(s) expertise(s) sobre o autismo", Clarice Rios deixa claro como "boa parte do que fazem os experts em autismo (e aqui se incluem tanto pais quanto terapeutas profissionais) é ajudar pessoas com autismo a desenvolver habilidades e obter conhecimento que não são de fato especializados" (p. 238). Em outras palavras, o que experts precisam ser capazes de traduzir para as pessoas autistas são "as habilidades e o conhecimento básicos que as pessoas adquirem em virtude de fazerem parte de uma determinada sociedade e que os ajudam a se orientar nas interaçóes que compóem sua vida cotidiana" (p. 238). Para a autora, "se especializar em autismo é desenvolver um determinado modo de atenção com relação à competência social cotidiana não especializada" (p. 238), é aprender a "tornar explícito o seu conhecimento tácito do mundo social", "transformar conhecimento tácito em conhecimento explícito" (p. 251). Como nos "experimentos de ruptura" de Harold Garfinkel (1967), que forçam uma incômoda explicitação de pressupostos implícitos básicos para a definição de uma interação, a pesquisa etnográfica de Rios é capaz de desdobrar o "balé muito gracioso e bem ensaiado" das "práticas de tradução radical" (p. 248), realizadas pelos experts, entre as pessoas com autismo e o mundo social que as envolve - um trabalho "amoroso" de tradução (Chew, 2013, p. 315). As inegáveis dificuldades das crianças autistas para corresponderem às expectativas de seu mundo social exigem, segundo Rios, "um aprendizado permanente" (p. 249). Fundamental para as famílias acompanhadas por Rios é " $[\mathrm{d}]$ istinguir entre o que é determinado pelo autismo e o que faz parte da personalidade e da trajetória singular da criança", distinguir entre comportamentos que exigem atenção especial, e uma "simples birra infantil", frente à qual a criança deve ser tratada "como qualquer outra criança crescendo naquele ambiente específico" (p. 249-50). Como mediaçóes entre seus filhos autistas e a sociedade, pais, mães e outras pessoas cultivam um ambiente social mais aberto à diferença, ao mesmo tempo em que favorecem a socialização de pessoas singulares.

No capítulo S.A.: classificação, interpelação, o filósofo Enrico Valtellina propõe a rica ideia de "diagnóstico como evento" que "ressignifica a vida da pessoa", produzindo um "efeito catártico" de "conscientização" e "autoabsolviçãa”" (p. 274). Como "evento”, Valtellina encontra na interpelação disparada por seu diagnóstico de SA o gatilho de uma transformação existencial em 
duas etapas. Num primeiro momento, Valtellina viu-se interpelado pelo diagnóstico de SA, sujeitando-se à sua tipificação biomédica, consolidada por Lorna Wing em 1981 (e.g.: "comunicação não verbal deficitária", "inabilidade de lidar com regras e códigos sociais, e normas sociais implícitas”, p. 266-7). O filósofo justifica essa sujeição inicial ao diagnóstico de SA pelo "efeito catártico ativado pela descoberta de um motivo para todas essas coisas" (p. 270): "Depois de passar uma vida inteira levando a culpa por essas desinclinaçóes, pessoas com problemas relacionais encontram no diagnóstico uma justificativa que as absolve" (p. 271). Num segundo momento, porém, "o tema da SA revelou-se" para Valtellina como essencialmente "um ordenamento cultural de tipos humanos que são divergentes - legitimamente divergentes - e que encontram formas infinitamente diferentes de compensar a escassa tolerância social pelas transgressóes involuntárias de códigos implícitos da interação cara a cara” (p. 278). Diante dessa percepção, Valtellina deixou, então, "legitimamente", de responder ao diagnóstico: "[a]gora, se me chamam, eu não me viro, e isso me parece a mais deliciosa das reações autistas" (p. 278).

Ainda na Parte III, o capítulo A quem pertence o autismo? Economia, fetichismo e stakeholders, de Roy R. Grinker, pode ser considerado uma introdução à "economia do autismo", na qual vislumbramos como "o autismo alimenta uma indústria de terapeutas; medicinas complementares e alternativas; medicamentos; educadores especiais; residências terapêuticas; e outras instalaçôes"; "novos fenômenos apoiam-se em fontes de capital, que incluem filantropos, organizaçóes de ativismo, escolas, governos, fundaçóes de pesquisa e pesquisadores carentes de recursos" (p. 288). A Parte III se encerra com o valioso Comentário: do que estamos falando quando falamos sobre autismo?, em que M. Ariel Cascio retoma pontos levantados pelos capítulos, buscando mostrar como eles "usaram o autismo como uma perspectiva para explorar questôes clássicas [“da Antropologia”], mas também usaram essas questóes clássicas para entender como o autismo se tornou uma perspectiva táo popular para essa investigação" (p. 320).

O livro conclui com duas reflexóes finais bastante distintas, na Parte IV. Em "Antropologia psicológica e o estudo da deficiência", Weisner elabora uma leitura ao mesmo tempo ampla e circunstanciada dos estudos de deficiência, em especial de TEA, no campo da Antropologia Psicológica, e em especial no caso dos textos incluídos no volume. Mostra-se especialmente relevante seu argumento de que " $[\mathrm{o}] \mathrm{s}$ portadores de TEA e outras deficiências são como nós em muitos sentidos", pois "podemos ver em seu desenvolvimento e sua vida muitos dos mesmos processos sociais, preocupaçóes e medos sobre não corresponder a expectativas, que todos nós de certa forma temos" (p. 335). "[T] odos nós precisamos de algum grau de tolerância social" conclui Weisner, pois se trata sempre de "passar por se sentir suficientemente competentes, agir de modo suficientemente normal e ser capaz de oferecer uma justificativa aceitável quando somos socialmente incompetentes" (p. 335). Não eram justamente os limites dessa "tolerância social" que os "experimentos de ruptura" de Garfinkel (1967) buscavam explorar? Em Alegria, último texto do livro, a antropóloga Prince-Hughes argumenta, na mesma direção de Weisner, mas de outra forma, que “podemos substituir a palavra 'autismo' pela expressão 'ser um ser vivente" (p. 352), pois "o que se pede das pessoas no espectro se espera de todas as pessoas". "Do microcosmo das pessoas do espectro até o mundo mais amplo", afirma Prince-Hughes, "é um passo natural descobrir a nossa expertise nas conexóes que nos sustentam e nos modos como impactamos tudo o que nos circunda" (p.351). De maneira forte e generosa, a antropóloga fecha o seu capítulo definindo o seminário que deu origem a esse livro como "um exercício de alegria sinérgica" (p. 354), i.e., um exercício para sermos "cada respiração, cada gole, cada mordida e cada átomo sensível e em movimento de cada um de nós” (p. 349).

Relativamente ao campo específico das Ciências Sociais, o livro mostra convincentemente o enorme potencial presente no estudo socioantropológico do autismo, em particular no que se refere à investigação de processos que envolvem a explicitação e especificação de pressupostos básicos (e geralmente implícitos) das "maneiras de agir, pensar e sentir" (Durkheim, 1995) que instituem a vida social. Como aponta a introdução das organizadoras, o livro evidencia plenamente os avanços em nosso conhecimento sobre 
"as circunstâncias históricas, culturais e econômicas" do autismo, sobre o autismo "no contexto da política, economia, estética e cidadania” (p. 27). Gostaria aqui de destacar o interesse de análises microssociológicas e interacionais das especificidades da "experiência autista” (Costa e Grinker, p. 199), mais interessadas em compreender o autismo como "modo de engajamento" (Fein), como "tipos humanos que são [...] legitimamente divergentes", e nas "formas infinitamente diferentes" (Valtellina, p. 278) que precisam ser desenvolvidas para que essa experiência possa ocorrer. Gostaria de destacar também o tema já tradicional (Bettelheim, 1959; Silberman, 2001; Baron-Cohen, 2012) da relação entre autismo e tecnicidade, ainda pouco desenvolvido para além de um "cliché redutor" (McGrath, 2017, p. 5), e que apenas o capítulo de Fein aborda, brilhantemente aliás, no livro. ${ }^{3}$

De maneira mais geral, o livro organizado por Rios e Fein revela o autismo como realidade humana e social: como história, legislação, mercado, política, arte, filosofia, linguagem, instituição, cultura, modo de vida, experiência vivida, sofrimento e alegria. Mostra, nas palavras de Cascio, que "autismo é um conceito (uma categoria, um rótulo, um tópico, uma ideia) que tanto descreve quanto constrói as experiências reais de pessoas reais, sejam elas experiências de sofrimento, alegria, criatividade, diversidade, orgulho etc.” (p. 311). Mostra, ainda, como notou Fein ecoando o comentário de Deleuze que abre esta resenha, o quão estranho é "desnomear" esse "estado de simbiose visível com os produtos da criação humana”, "chamar uma condição de íntima coexistência com o mundo exterior usando uma palavra que significa isolamento em si mesmo" (p. 170). Traduzir o autismo exige, aparentemente, mais do que atender às necessidades de uma pessoa, ou às expectativas sociais; exige o engajamento na cocriação de um mundo compartilhado possível, no qual as diferenças entre as pessoas - não apenas do "espectro autista", mas do amplo espectro humano possam ser mais bem aproveitadas por elas mesmas.

\section{Notas}

1 Dentre os critérios diagnósticos definidos pelo DSM5 para o "Transtornos do Espectro Autista" (TEA), destacam-se os "[d] éficits persistentes na comunicação social e na interação social" e os "[p]adrôes restritos e repetitivos de comportamento, interesses ou atividades" (APA, 2014, p. 50). Ainda segundo o DSM-5, o TEA pode apresentar três "níveis de gravidade": (1) "exigindo apoio"; (2) "[e]xigindo apoio substancial"; e (3) "[e]xigindo apoio muito substancial" (APA, 2014, p. 52). Nesta resenha, assim como no livro resenhado, usaremos preferencialmente o substantivo "autismo" para tratar do complexo sociocultural associado ao diagnóstico de TEA, e o adjetivo "autista" para qualificar a participação nesse complexo.

2 "Síndrome de Asperger" (SA) é o nome usado para aquilo que foi chamado de "Transtorno de Asperger" até o DSM-4, mas que foi eliminado como denominação independente no $D S M-5$, transformado entáo em "transtorno do espectro autista sem comprometimento linguístico ou intelectual” (APA, 2014, p. 32).

3 Ligados e essa segunda via de investigação, mas com mais material já acumulado, estáo estudos sobre autismo e gênero que oferecem estimulantes alternativas às equiparaçóes simplistas entre autismo, tecnicidade e masculinidade (e.g.: Jack, 2014; Yergeau, 2018; Willey et al., 2015).

\section{Referências}

APA (American Psychiatric Association). (2014), Manual diagnóstico e estatístico de transtornos mentais: DSM-5. Tradução de Maria I.C. Nascimento; Paulo H. Machado; Regina M. Garcez; Régis Pizzato; Sandra M. Mallmann da Costa. Porto Alegre, ArtMed.

BARON-COHEN, Simon. (2012), "Autism and the technical mind". Scientific American, 307, 5: 72-5.

BETTELHEIM, Bruno. (1959), "Joey: a 'mechanical boy". Scientific American, 200, 3: 116-27.

CHEW, Kristina. (2013), "Autism and the task of the translator", in: J. Davidson \& M. Orsini (eds.), Worlds of autism: across the spectrum of neurological difference, Minneapolis, University of Minnesota Press, pp.305-17.

DELEUZE, Gilles. (2016), "Esquizofrenia e sociedade”, in: Dois regimes de loucos: textos e entrevistas (1975-1995). Tradução de Guilherme Ivo. São Paulo, Ed.34, pp.22-34.

DURKHEIM, Émile. (1995), As regras do método sociológico. Tradução de Paulo Neves. São Paulo, Martins Fontes.

FEIN, Elizabeth; RIOS, Clarice. (2016), “Autism Spectrum Disorders: global, local and personal perspectives: a conference report”. Somatosphere. Disponível em: http:// somatosphere.net/2016/autism-spectrum-disorders- 
in-global-local-and-personal-perspective-a-conferencereport.html/, consultado em 10/01/2020.

FEIN, Elizabeth; RIOS, Clarice (eds.). (2018), Autism in translation: an intercultural conversation on autism spectrum conditions. Cham, Palgrave MacMillan.

GARFINKEL, Harold. (1967), Studies in ethnomethodology. Englewood Cliffs, Prentice-Hall.

JACK, Jordynn. (2014), Autism and gender: from refrigerator mothers to computer geeks. Urbana, University of Illinois Press.

McGRATH, James. (2017), Naming adult autism: culture, science, identity. Londres, Rowman \& Littlefield.
SILBERMAN, Steve. (2001), “The geek syndrome”. Wired 9: 12 .

YERGEAU, Melanie. (2018), Authoring autism: on rhetoric and neurological queerness. Durham, Duke University Press.

WILLEY, Angela, SUBRAMANIAM, Banu, HAMILTON, Jennifer A. \& COUPERUS, Jane. (2015), “The mating life of geeks: love, neuroscience, and the new autistic subject”. Signs 40, 2:369-91.

Resenha recebida em: 13/01/2020

Aprovada em: 11/05/2020 